\title{
CHANGES OF GLOMERULAR CAPILLARY WALL IN AMINONUCLEOSIDE NEPHROSIS OF RATS
}

\author{
Hiroshi Maeda \\ Research Institute of Drug Safety, Setsunan University \\ Toshio Abe and Hiroaki Miyajima \\ Drug Safety Evaluation Laboratories, Central Research Division, Takeda Chemical Industry Co. Ltd.
}

\begin{abstract}
Puromycin aminonucleoside (PAN) at a dose of $1.67 \mathrm{mg} / 100 \mathrm{~g}$ body weight was injected subcutaneously for 10 days into male Sprague-Dawely rats. The mean urinary protein excretion of the PAN-treated rats was more than 80 times as much as that of the control rats. In light microscopy. swelling and vacuolation of glomerular epithelial cells, and slight thickening of mesangial area were found, but the glomerular basement membrane was not involved. Lysozyme binding was reduced in the lamina rara externa and interna of the glomerular basement membrane and the epithelial surface. Eight sorts of lectins were used to examine alterations in the oligosaccharide chain. Binding of Bauhinia purpurea (BPA) with the capillary wall was markedly increased in PAN-treated rats. The binding of Glycine $\max (\mathrm{SBA})$ showed a pattern similar to BPA, but the increment was much less. Thus the alteration of the oligosaccharide chains of the glomerular capillary wall might have a close relationship to the development of proteinuria in PAN-treated rats. (J Toxicol Pathol $2: 203 \sim 212,1989$ )

Key worls: Puromycin aminonucleoside, Nephrosis, Anionic site, Lectin binding
\end{abstract}

\section{Introduction}

Since first described in $1955^{1}$, puromycin aminonucleoside (PAN) has been used widely to produce an experimental animal model of minimal change nephropathy in man, which is characterized by marked proteinuria. This experimental model of nephrosis has been studied extensively using morphologic and physiologic techniques, but the mechanism of the proteinuria has not been elucidated. Morphologically, PAN induces extensive fusion of the glomerular epithelial cell foot processes.3. The glomerular capillary wall contains negatively charged macromolecules ${ }^{4-\bullet}$ rich in heparansulfate-proteoglycan ${ }^{7-0}$ in the glomerular basement membrane (GCM) and sialoproteins in

前田阿部男官空究钐

Accepted for publication: April 11, 1989

Mailing address : Hiroshi Maeda, Research Institute of Drug Safety. Setsunan University, 45-1, Nagaotoge-cho, Hirakata-shi, Osaka-fu, 573-01, Japan.

- Part of this paper was presented at the 3rd Annual Meeting of the Japanese Society of Toxicologic Pathology held in Nagoya, February 6-7 (Maeda et al. 1987) the glomerular epithelial cell surface coat ${ }^{10,11}$. These anionic sites are thought to regulate the flow of plasma macromolecules across the GBM, since polycation such as polyethyleneimine results in increased permeation of anionic proteins with the use of native (anionic) ferritin as the tracer $^{12}$. And cationic or neutral molecules can more easily penetrate into the GBM than anionic molecules $^{13-18}$. It has been suggested that proteinuria seen in aminonucleoside nephrosis may be a result of the loss of anionic sites of the glomerular capillary wall ${ }^{17-21}$. However, some discrepancies were observed in autoradiographic tracer studies with ${ }^{125}$ I-cationic ferritin as the cationic probe ${ }^{22}$. Other investigators have suggested that detachment of the epithelial cell foot processes from the underlying GBM results in an enhanced permeability for large molecules to pass into the urinary space ${ }^{23-25}$.

In vitro exposure of PAN to glomerular epithelial cells was shown to cause alteration of the glycoprotein synthesis ${ }^{26}$. However, no morphological study on the alteration of the glycoprotein has been made. In this study, we ex- 
amined the charge alterations utilizing lysozyme as a cationic probe and changes of oligosaccharide chains in the glomerular capillary wall of PANtreated rats.

\section{Materials and Methods}

Male Sprague-Dawley rats (Japan CLEA Inc.) aged 5 weeks were used in this study. Puromycin aminonucleoside (PAN) [6-dimethylamino-9-(3'amino- $3^{\prime}$-deoxyribosyl) purine], and egg white lysozyme (grade 1) were purchased from Sigma Chemical Company, St. Louis, Missouri, USA. Lectin staining kits were bought from $E-Y$ Laboratories, Richmond, California, USA.

Production of Nephrosis

To induce nephrosis, the animals were daily injected subcutaneously with PAN in a dose of $1.67 \mathrm{mg}$ per $100 \mathrm{~g}$ body weight given as a $0.5 \%$ solution in normal saline. Control animals were injected with an equal volume of normal saline. Throe separate experiments were carried out using a total of 24 PAN-treated animals and 24 concurrent controls. The dosage was calculated to the nearest $0.01 \mathrm{ml}$. All animals were sacrificed 11 days after injection.

\section{Measurement of Proteinuria}

Twenty-four-hour urine samples were collected and total protein excretion was determined by the Coomassie Brilliant Blue G-250 with Protein Assay Kit according to the methods of Bradford ${ }^{27}$. The animals were kept without food but with water ad libitum. The examination was performed on day $2,4,6,8$, and day 10 after injections.

\section{Lysozyme Perfusion Experiments}

The examinations were performed on day 11 after injection. Four animals each from PANtreated and control groups were anesthetized by intraperitoneal injection of sodium pentobarbital. Kidneys were perfused in a retrograde manner through the thoracic aorta with 2-3 $\mathrm{ml}$ of KrebsRinger solution, $\mathrm{pH} 7.4$, followed by $20 \mathrm{ml}$ of a solution containing $3 \%$ lysozyme. Perfusion was accomplished with a Harvard infusion pump at a rate of $10 \mathrm{ml}$ per min. The kidneys perfused with lysozyme were fixed in Karnovsky's aldehyde fixative ${ }^{28}$. Blocks from these kidneys were immersed in the same fixative for an additional $2 \mathrm{hrs}$, postfixed in 1\% OsO, in acetate-veronal buffer, $\mathrm{pH}$ $7.2,4^{\circ} \mathrm{C}$, for $1 \mathrm{hr}$ and stained in block with uranyl acetate before dehydration ${ }^{20}$. The tissues were then processed routinely for electron microscopy. Ultrathin sections were stained with uranyl acetate and lead citrate and examined by an electron microscope (JEM-1200EX, JEOL Co. Ltd.).

\section{Lectin Binding Study}

The examinations were performed on day 11 after injection. Four animals from each group were perfused as described above. The kidneys were perfused with Ringer solution followed by fixative consisting of $0.1 \%$ glutaraldehyde, $4 \%$ paraformaldehyde, $0.2 \mathrm{mM} \mathrm{CaCl} \mathrm{m}_{2}$ in $0.1 \mathrm{M}$ phosphate buffer ( $\mathrm{pH}$ 7.4). Blocks from these kidneys were additionally fixed with the similar fixatives without glutaraldehyde for $\mathbf{4 8} \mathrm{hrs}$ at room temperature and processed by the conventional paraffin embedding methods. Four $\mu \mathrm{m}$ thick paraffin sections were stained with biotinylated lectins followed by incubation with avidin-HRP.

For staining experiments, sections were deparaffinized, washed in Tris buffered saline (TBS) or pH 7.4 phosphate buffered saline (PBS), incubated for $1 \mathrm{hr}$ at room temperature with biotinylated lectin. The sections were then rinsed several times with TBS or PBS, incubated with HRP-avidin for I hr at room temperature, stained with 3, $3^{\prime}$-diaminobenzidine, and counterstained with hematoxylin.

The sources of lectins, their abbreviated names, and nominal specificities of sugar are listed in Table 1. Lectins were diluted in TBS or PBS supplemented with $\mathrm{Ca}^{+}$and $\mathrm{Mg}^{+}$ions and used in concentrations ranging from 20 to $200 \mu \mathrm{g}$ per $\mathrm{ml}$.

No staining was observed in the specificity study with the lectin solutions mixed by an adequate density of the specific sugar.

\section{Results}

\section{Proteinuria}

The mean protein excretion was plotted against time in Fig. 1.

In PAN-treated rats, urinary protein increased within 8 days, then rose sharply to 351.1 $\mathrm{mg} /$ day on 10 days after administration. The mean urinary protein excretion on the day prior to sacrifice was more than 80 times as much as that of 


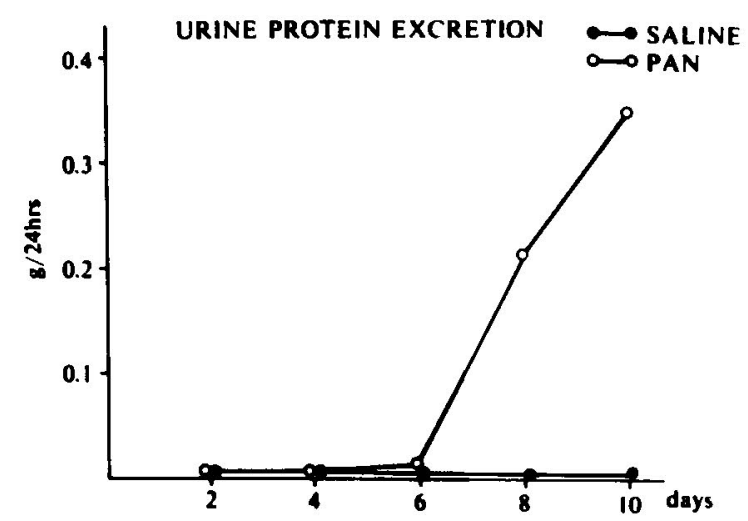

Fig. 1. Twenty-four-hour urine protein following administration of PAN or saline.

the control group.

Control animals injected with saline alone excreted 1.6 to $4.3 \mathrm{mg} /$ day of protein, with no significant increase during the experimental period.

Light Microscopy

In PAN-treated rats, glomerular epithelial cells were swollen, vacuolated, and sometimes adhered to the Bowman's capsule (Fig. 2). The mesangial area was slightly thickened in some glomeruli, but was of normal cellularity (Fig. 2). Delineation of the GBM was not seen in any glomeruli. The tubular epithelium was flattened with dilatated tubules and frequently contained hyaline droplets. Hyaline casts were frequently seen. Control animals showed no remarkable changes.

\section{Lysozyme Perfusion Study}

In control animals, there were no changes in any glomerular component. Lysozyme bound to the entire epithelial cell membrane, which was clearly outlined by a uniform dense staining area ; dense deposition of lysozyme was seen in the lamina rara externa (LRE) and interna (LRI) of the GBM. Lysozyme was distributed as discrete areas of increased electron density that arranged in a regular patterns in the GBM (Fig. 3a).

In PAN-treated animals, vacuolation, increment in lysosome. pinocytotic vesicles, and fusion of the foot process were observed in the glomerular epithelial cells. Endothelial and mesangial cells, however, maintained a rather normal structure. Lysozyme binding was reduced in all glomerular capillary walls ; the thickness of the layer on endothelial cells and fused foot processes of the glomerular epithelial cell was decreased, and the electron dense areas of lysozyme in the LRE and LRI of the GBM decreased both in size and number, and those in lamina densa (LD) showed a very slight reduction which was shown as decreased electron density (Fig. 3b).

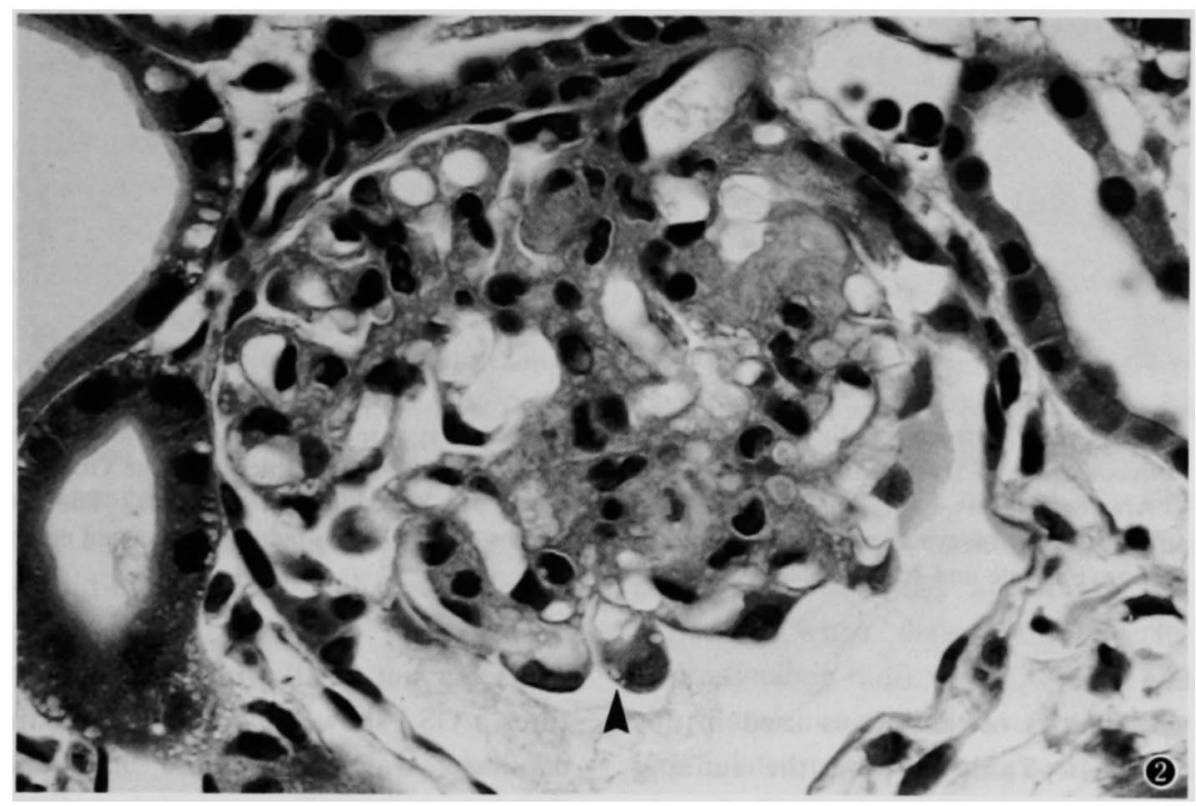

Fig. 2. Light micrograph from a PAN-treated rat glomerulus. Glomerulus shows segmental mesangial thickening, vacuolation of glomerular epithelial cells (arrowhead), and focal adhesion between Bowman's capsule and glomerular epithelial cells. (H.E., $\times 780$ ) 


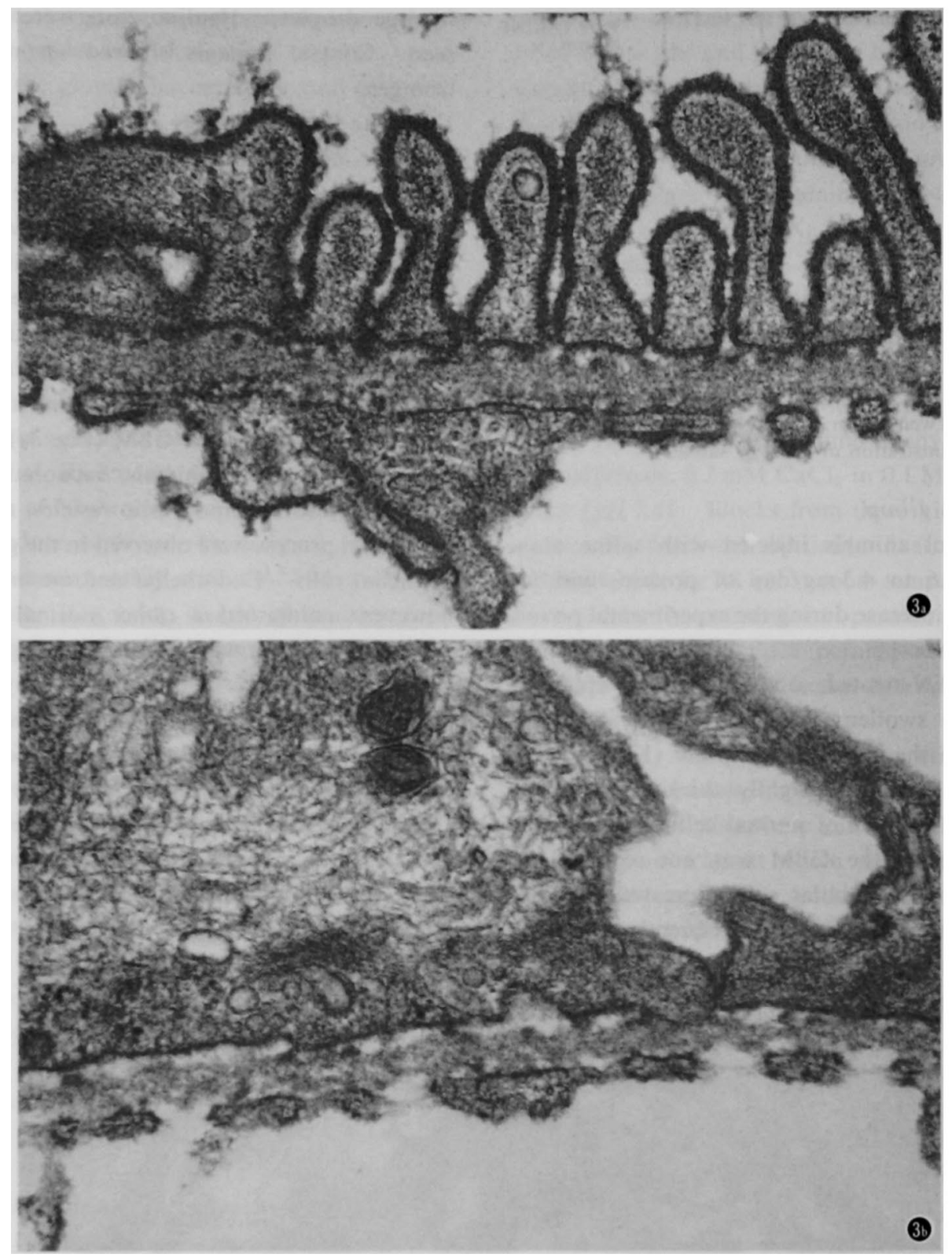

Fig. 3. Electron micrograph from rat glomerular capillary wall perfused with lysozyme. (a) Saline control rat: lysozyme binding is seen as a uniform dense layer in epithelial cell membranes and discrete areas of increased electron density in lamina rara externa and interna of the GBM. (b) PAN-treated rat : lysozyme layer on fused foot processes is reduced in thickness. The dense deposition of lysozyme in lamina rara externa and interna of the GBM is reduced in size and number. (Uranyl acetate and lead citrate, $\times 54,300$ )

\section{Leetin Binding Study}

Sugar specificities of the lectins used in this study are listed in Table 1 . And the staining patterns of the lectins are shown in Table 2.

In control rats, BPA (Fig. 4a), SBA (Fig. 5a), PNA, and Con $A$ reacted faintly with capillary walls but not at all with other glomerular structures. GS I showed more intense binding with the capillary wall than those mentioned above. WGA gave most intense staining along the capillary wall and mesangium, and it also reacted weakly with Bowman's capsule. Con A showed 
Table 1. Lectins Used in This Study

\begin{tabular}{|c|c|c|}
\hline Lectins From & Abbreviations & Sugar Specificitya \\
\hline Bauhnia purpurea & BPA & D-GalNAc > D-Gal \\
\hline Glycine Max (Soy bean) & SBA & $\alpha$-D-GalNAc $>\beta-D-G a I N A c>\alpha-D-G a l$ \\
\hline Griffonia simplicifolia & GS 1 & $\alpha-\mathrm{D}-\mathrm{Gal}$ \\
\hline Arachis hypogaea (Peanut) & PNA & Gal-pl-3-GalNAc, D-Gal \\
\hline Dorichos biflorus & DBA & $\alpha-D-G a I N A c$ \\
\hline Urex europaeus & UEA 1 & $\alpha-L-F u c o s e$ \\
\hline Triticum vulgaris & WGA & $\begin{array}{c}\beta-\text { D-GlcNAc, }(\text { GlcNAc) })_{1} \geq(\text { GlcNAc })_{3}> \\
(\text { GlcNAc) })_{2}>\text { GlcNAc, NeuNAc }\end{array}$ \\
\hline Canavalia ensiformis (Jack bean) & Con A & $\alpha-\mathrm{D}-\mathrm{Man}>\boldsymbol{\alpha}-\mathrm{D}-\mathrm{Glc}$ \\
\hline
\end{tabular}

a : Abbreviations used are GlcNAc, $\mathbf{N}$-acetylglucosamine: GalNAc, $\mathbf{N}$-acetylgalactosamine; NeuNAc, N acetylneuraminic acid (sialic acid) : Gal, galactose; Glc, glucose : Man, mannose.

Table 2. Binding Patterns of Lectins

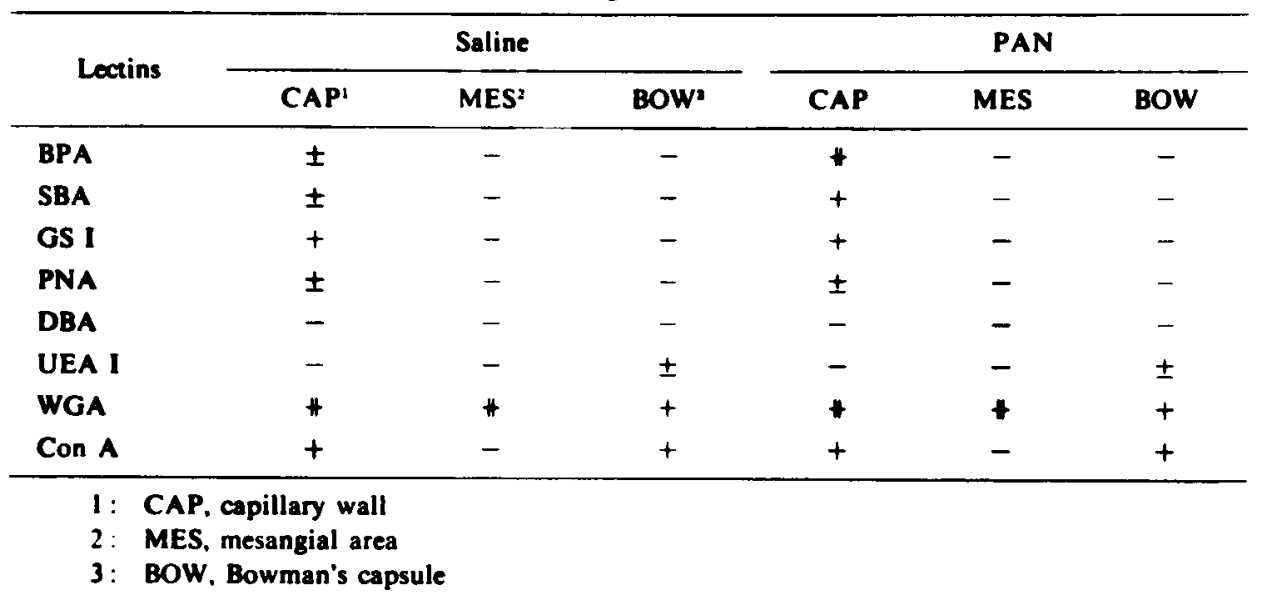

up more weakly but yielded similar binding patterns compared to WGA. UEA I reacted only with Bowman's capsule. DBA was the only lectin examined which failed to react with glomeruli.

In PAN-treated rats, binding of BPA with the capillary wall was markedly increased (Fig. 4b). But the bindings of BPA with the other glomerular component seemed not to change. Bindings of SBA showed changes similar to those of BPA but the degree of change was much less (Fig. 5b). Other lectins did not exhibit any changes compared to the control.

\section{Discussion}

We studied the animals at day 11 when the urinary protein excretion was 80 times (mean values of $351.1 \mathrm{mg} / \mathrm{day}$ ) as much as the control rats (mean values of $4.3 \mathrm{mg} / \mathrm{day}$ ).
It has been observed electron-microscopically that the negative charge was distributed in glomerular capillary walls with the use of lysozymes, cationized ferritin ${ }^{4}$, ruthenium red ${ }^{4}$, polyethyleneimine, and others as the cationic probe. It has also been shown that the net electrical charge of the plasma macromolecule is an important determinant of its fractional clearance by use of dextran 13 , ferritin ${ }^{14-16}$, and others: The fractional clearance of neutral molecules is higher than that of anionic molecules and lower than cationic molecules when these molecules have similar hydrodynamic radii.

Numerous studies have shown that proteinuria is related to the charge alteration of the glomerular capillary wall17-21 : Loss of anionic sites in GBM and the glomerular epithelial cells causes the leakage of plasma proteins which have mostly 


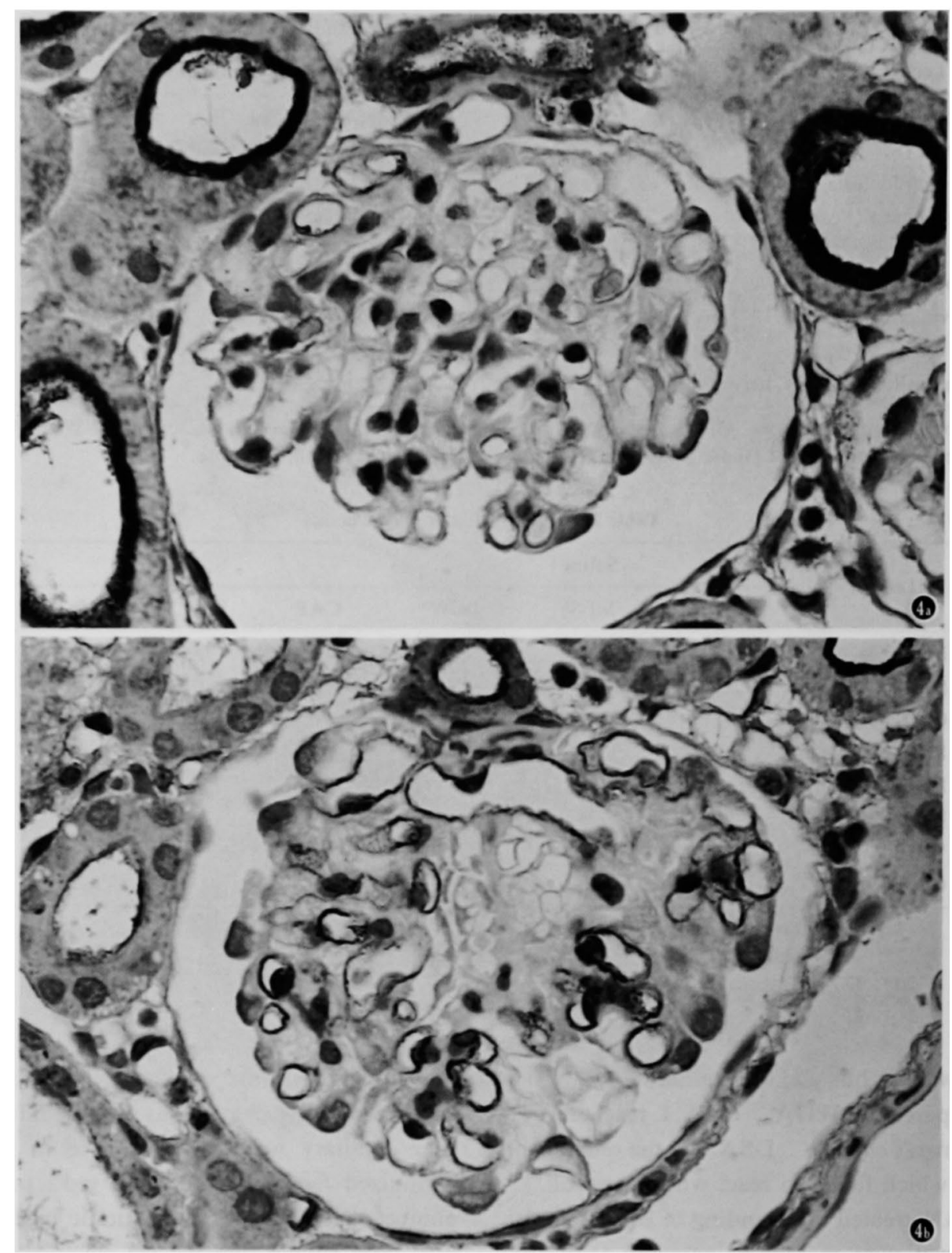

Fig. 4. Light micrograph from rat glomerulus stained with BPA. (a) Saline control rat ; BPA reacts faintly with capillary walls. (b) PAN-treated rat; binding of BPA with the capillary walls is markedly increased. (avidin-biotin HRP, $\times 780$ )

negative charge in rats. Similar changes were observed in human minimal change nephropathy ${ }^{30.31}$. Recently, enhancement of nephrotic changes by co-administration of protamine (cationic protein) was shown in PAN-treated rats $^{32}$.

Our studies also showed that the lysozyme bindings were markedly reduced in the lamina rara externa and interna of the GBM and the glomerular epithelial and endothelial cell surface. Fusion of foot process which was also demonstrated in our study has also been thought to be related to the loss of anionic sites ${ }^{12,88,24}$.

Some investigators have shown that focal detachment of the glomerular epithelial cells from GBM causes the leakage of the plasma 

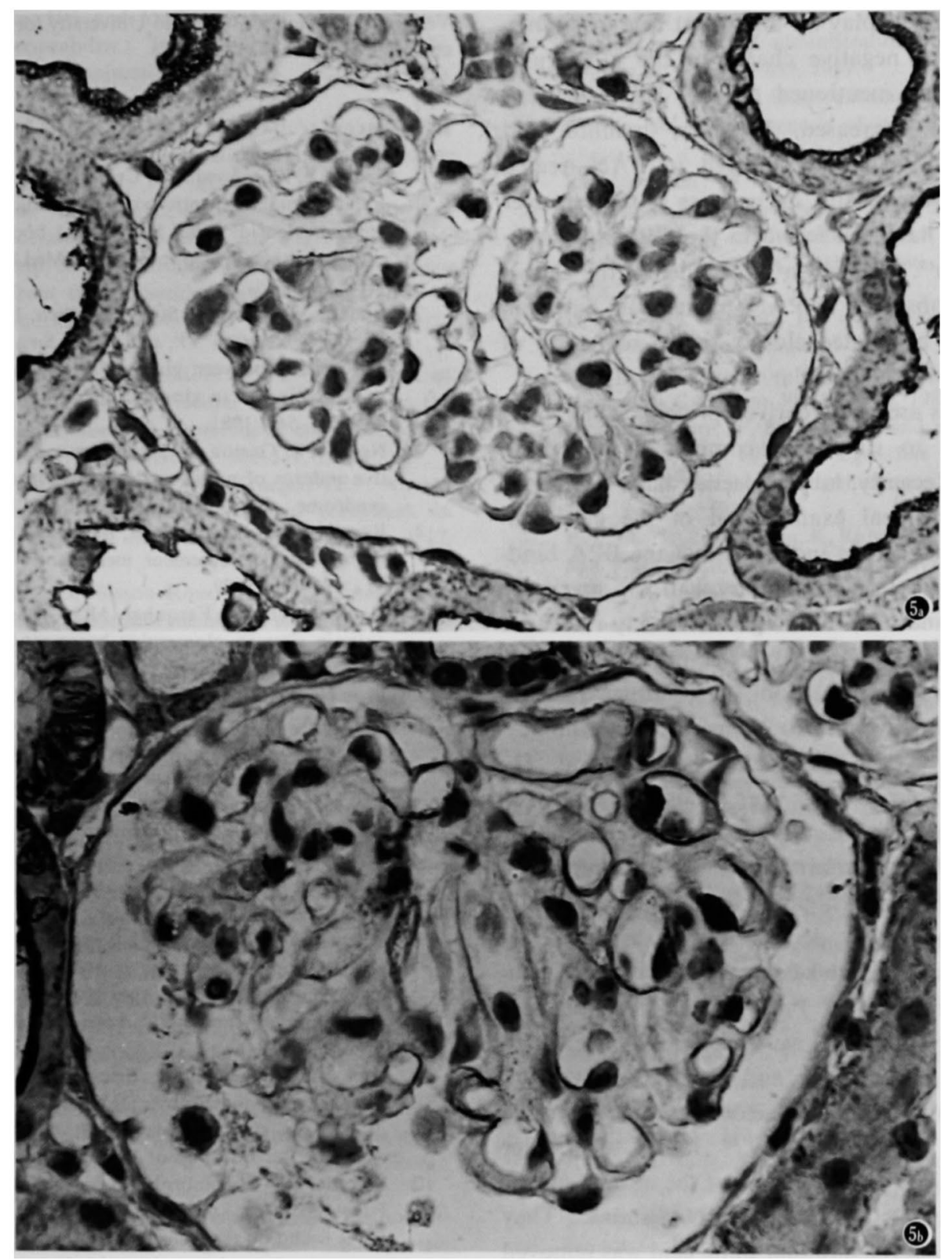

Fig. 5. Light micrograph from rat glomerulus stained with SBA. (a) Saline control rat; SBA reacts with the same pattern as BPA (Fig. 4. (a)). (b) PAN-treated rat; binding of SBA with the capillary walls is slightly increased in some glomerular tufts. (avidin-biotin-HRP, $\times 780$ )

proteins $^{23-25}$. Since our studies revealed that detachment of the glomerular epithelial cells or rupture of the GBM was not seen, those changes are thought to occur rarely.

Biochemical characterizations of the GBM and glycocalyx of the glomerular epithelial cells or endothelial cells have been complemented by gel electrophoresis and immunohistochemistry. Type
IV ${ }^{35.36}$ and $V$ collagens ${ }^{37.38}$, proteoglycans such as heparan sulfate proteoglycan (HS-PG) ${ }^{39-41}$, laminin ${ }^{36,42}$, entactin ${ }^{43}$ are believed to be integral component of the GBM.

In recent years, podocalyxin which is rich in sialic acid glycoprotein was found in the glycocalyx of the glomerular epithelial cells or endothelial cells ${ }^{10}$. HS-PG and podocalyxin have 
been thought to play an important role in maintenance of the negative charge of the glomerular capillary wall mentioned above. Histochemically, HS-PG decreased, however, laminin and podocalyxin were not changed in PAN-treated rats ${ }^{4}$. Biochemically, an increase of the turnover of HS-PG has been found in the GBM of PANtreated rats ${ }^{45}$. Based on this evidence, the charge alteration observed in PAN-treated rats has been thought to be related closely to the reduction of HS-PG in the glomerular capillary wall.

Lectins are plant-derived proteins which bind specifically to simple or complex carbohydrate groups. Recently, labeled lectins have been used for histochemical examination of the glycoconjugate. Our results indicated that the BPA binding to the glomerular capillary wall was markedly increased and SBA binding was weakly increased in PAN-treated rats. But the other 6 sorts of lectins were not changed in binding. Because BPA specifically bind to $\mathrm{N}$-acetylgalactosamine ${ }^{40}$ and SBA to $\mathbf{N}$-acetylgalactosamine and $\mathrm{D}$ galactose ${ }^{47}$, our findings were thought to simply be an increment of those oligosaccharide elements or changes of the conformations of oligosaccharide chains. Other investigation have shown that sialic acid was markedly decreased whereas galactose, glucose, mannose, and hexosamine were not changed in the GBM of PAN-treated rats"s. Some types of glycoproteins were known to have terminal sialic acid residue and also have $\mathbf{N}$-acetylgalactosamine and $\mathbf{D}$-galactose residue within the molecule. Stoward et al." found that after sialidase digestion. glomeruli of the normal mouse kidney became positive for PNA stains. They suggested that the terminal sialic acid was removed and galactosyl residue imparted affinity for PNA.

From these findings, we suggested that glycoproteins normally containing much sialic acid may be denatured or sialic acid-poor glycoproteins may be produced by the damaged epithelial cells, and $\mathbf{N}$-acetylgalactosamine and/or D-galactose which are ordinarily masked by sialic acid may be exposed to the molecular surface in the glomerular capillary wall in the PAN-treated rats.

Acknowledgements : The authors thank Dr. Chitoshi Itakura, Deprtment of Comparative Patholgy. Faculty of
Veterinary Medicine. Hokkaido University for their helpful criticism of the manuscript.

\section{References}

1. Frenk, S, Antonowicz, I, Craig JM, and Metcoff J: Experimental nephrotic syndrome induced in rats by aminonucleoside renal lesions and body electrolyte composition. Proc Soc Exp Biol Med 89: 424-427. 1955.

2. Seefeldt, T, Bohman, SO, Gundersen, HJG, Maunsbach AB, Petersen VP, and Olsen S: Quantitative relationship between glomerular foot process width and proteinuria in glomerulonephritis. Lab Invest 44 : $541-546,1981$

3. Nevis, TE. Gaston, T, and Basgen, JM : Quantitative indexes of aminonucleoside-induced nephrotic syndrome. Am J Pathol 117 : 30-36, 1984.

4. Kanwar, YS and Farquhar, MG : Anionic sites in the glomerular basement membrane. J Cell Biol 81 : 137-153, 1979.

5. Caulfield, JP and Farquhar, MG : Distribution of anionic sites in glomerular basement membranes: their possible role in filtration and attachment. Proc Natl Acad Sci USA 73: 1646-1650, 1976.

6. Pilia, PA, Swain, RP, Williams, AV, Loadhoit, CB, and Ainsworth SK : Glomerular anionic site distribution in nonproteinuric rats. Am J Pathol 121: 474-485, 1985.

7. Linker, A, Hovingh, P, Kanwar, YS, and Farquhar, MG : Characterization of heparan sulfate isolated from dog glomerular basement membranes. Lab Invest 44: 560-565, 1981.

8. Kanwar, YS, Rosenzweig. U, and Jakubowski, ML : Distribution of de novo synthesized sulfated glycosaminoglycans in the glomerular basement membrane and mesangial matrix. Lab Invest 49: 216-225, 1983.

9. Klein, DJ, Oegeme, TR, Eisenstein, R, Furcht, L, Micheel, AF, and Brown, DM : Renal localization of heparan sulfate proteoglycan by immunohistochemistry. Am J Pathol 111 : 323-330, 1983.

10. Sawada. H, Stukenbrok, H, Kerjaschki, D, and Farquhar, MG: Epithelial polyanion (podocalyxin) is found on the sides but not the soles of the foot processes of the glomerular epithelium. Am J Pathol 125: $309-317,1986$.

11. Faraggiana, T and Grishman, E: The podocyte cell coat in experimental nephrosis. J Ultrastruct Res 74: 296-306, 1981.

12. Barnes, JL, Radnik, RA, Gilchrist, EP, and Venkatachalam, MA : Size and charge selective permeability defects induced in glomerular basement membrane by polycation. Kidney Int 25 : 11-19, 1984.

13. Chang, RLS, Deen, WM, Robertson, CR, and Brenner BM : Permselectivity of the glomerular capillary wall : III. Restricted transport of polyanions. Kidney Int 8: 212-218, 1975.

14. Rennke HG, Cotran, RS, and Venkatachalam, MA : Role of molecular charge in glomerular permeability. J Cell Biol 67 : 638-646, 1975. 
15. Rennke, HG and Venkatachalam, MA : Glomerular permeability : in vivo tracer studies with polyanionic and polycationic ferritins. Kidney Int 11 : 44-53, 1977.

16. Cohen, S, Vernier, RL, and Michael AF: The effect of charge on the renal distribution of ferritin. Am J Pathol 110: 170-181, 1983.

17. Michael, AF, Blau, E, and Vernier, RL: Glomerular polyanion. Lab Invest 23 : 649-657, 1970.

18. Caulfield, JP and Farquhar, MG : Loss of anionic sites from the glomerular basement membrane in aminonucleoside nephrosis. Lab Invest 39 : 505512, 1978.

19. Caulfield, JP: Alterations in the distribution of alcian blue-staining fibrillar anionic sites in the glomerular basement membrane in aminonucleoside nephrosis. Lab Invest 40: 503-511, 1979.

20. Seiler, MW, Hoyer, JR, and Krueger, TE: Altered localization of protamine-heparin complexes in aminonucleoside nephrosis. Lab Invest 43 : 9-17. 1980.

21. Mahan, JD, Sisson-Ross, S, and Vernier, RL: Glomerular basement membrane anionic charge site changes early in aminonucleoside nephrosis. Am J Pathol 125: 393-40I, 1986.

22. Kanwar, YS and Jakubowski. ML: Unaltered anionic sites of glomerular basement membrane in aminonucleoside nephrosis. Kidney Int 25 : 613618, 1984.

23. Ryan, GB and Karnovsky, MJ : An ultrastructural study of the mechanisms of proteinuria in aminonucleoside nephrosis. Kidney Int 8 : 219-232, 1975.

24. Olson, JL, Rennke, HG, and Venkatachalam, MA : Alterations in the charge and size selectivity barrier of the glomerular filter in aminonucleoside nephrosis in rats. Lab Invest $44:$ :271-279. 1981.

25. Kanwar, YS and Rosenzweig. LJ : Altered glomerular permeability as a result of focal detachment of the visceral epithelium. Kidney Int 21 : 565-574. 1982.

26. Fishman, JA and Karnovsky, MJ : Effects of the aminonucleoside of puromycin on glomerular epithelial cells in vitro. Am J Pathol 118 : 398407. 1985.

27. Bradford, MM : A rapid and sensitive method for the quantitation of microgram quantities of protein utilizing the principle of protein-dye binding. Anal Biochem 72: 248-254, 1976.

28. Karnovsky. MJ : A formaldehyde-glutaraldehyde fixative of high osmolality for use in electron microscopy. J Cell Biol 27 : 137A, 1965.

29. Farquhar, MG and Palade, GE : Cell junctions in amphibian skin. J Cell Biol 26 : 263-29l, 1965.

30. Blau, EB and Haas, JE : Glomerular sialic acid and proteinuria in human renal disease. Lab Invest 28 477-481, 1973.

31. Bridges, CR, Myers, BD, Brenner, MB, and Deen. WM: Glomerular charge alterations in human minimal change nephropathy. Kidney Int 22 : 677 684, 1982.

32. Saito, T, Sumithran, E, Glasgow, EF, and Atkins,
RC: The enhancement of aminonucleoside nephrosis by the co-administration of protamine. Kidney Int 32 : 691-699, 1987.

33. Seiler, MW, Rennke, HG, Venkatachalam, MA, and Cotran, RS: Pathogenesis of polycation-induced alterations ("fusion") of glomerular epithelium. Lab Invest 36 : 48-61, 1977.

34. Kerjaschki D : Polycation-induced dislocation of slit diaphragms and formation of cell junctions in rat kidney glomeruli. Lab Invest 39: 430-440, 1978.

35. Contoy, PJ, Timpl, R, and Farquhar, MG : Comperative distribution of laminin, type IV collagen, and fibronectin in the rat glomerulus. J Histochem Cytochem 30 : 874-886, 1982.

36. Dean, DC, Barr, JF, Freytag, JW, and Hudson, BG : Isolation of type IV procollagen-like polypeptides from glomerular basement membrane. J Biol Chem 258 : 590-596, 1983.

37. Foidart, JM, Tryggvason, K, Robey, GP. Liotta, LA, and Martin, GR: Biosynthesis of type IV and V (alpha A-alpha B) collagens by human placenta. Collagen Related Res I: 137-141, 1981

38. Martinez-Hernandez. AS. Gay, S, and Miller, EJ Ultrastructural localization of type $V$ collagen in rat kidney. J Cell Biol 92 : 343-349, 1982.

39. Kanwar. YS and Farquhar. MG: Isolation of glycosaminoglycans (heparan sulfate) from glomerular beasement membrane. Proc Natl Acad Sci USA 76: 4493-4497, 1979

40. Kanwar, YS and Farquhar, MG : Detachment of endothelium and epithelium from the glomerular basement membrane produced by kidney perfusion with neuraminidase. Lab Invest 42 : 375-384, 1980.

41. Kanwar, YS, Veis, A. Kimura, JH. and Jakuboski, ML: Characterization of heparan sulfate proteoglycan of glomerular basement membrane. Proc Natl Acad Sci USA 81 : 762-766, 1984.

42. Madri. JA. Roll, FJ, Furthmayr, H, and Foidart, JM : Ultrastructural localization of fibronectin and laminin in basement membranes of murine kidney. J Cell Biol 86: 682-687, 1980

43. Carlin, B, Jaffe, R, Bender, B, and Chung, AE: Entactin, a novel basal lamina associated sulfated glycoprotein J Biol Chem 256: 5209-5214, 1981.

44. Mynderse, LA, Hassell, JR, Kleinman, HK, Martin, GR, and Martinez-Hernandez A : Loss of heparan sulfate proteoglycan from glomerular basement membrane of nephrotic rats. Lab Invest 48 : 292 302, 1983.

45. Klein, DJ, Dehnel, PJ, Oegema, TR, and Brown, DM: Alterations in proteoglycan metabolism in the nephrotic syndrome induced by the aminonucleoside of puromycin. Lab Invest 50: 543-551. 1984.

46. Kaifu, $R$ and Osawa, $T$ : Synthesis of $O-\beta-D$ galactopyranosyl-( $1 \rightarrow 3)$-O- $(2$-acetamido- 2 deoxy- $\alpha$ (and- $\beta$ )-D-galactopyranosyl)- $N$-tosyl- Lserine and their interaction with $D$-galactose-binding lectins. Carbohydrate Res 69: 79-88, 1979.

47. Goldstein, LJ and Hayer, CE : The lectins : carbo- 
hydrate-binding proteins of plants and animals. Adv Carbohyd Chem Biochem 35 : 127-340, 1978.

48. Blau, EB and Michael, AF : Rat glomerular glycoprotein composition and metabolism in aminonucleoside nephrosis. Proc Soc Exp Biol Med 141 :
164-172, 1972.

49. Stoward, PJ, Spicer, SS, and Miller RL: Histochemical reactivity of peanut lectin-horseradish peroxidase conjugate. J Histochem Cytochem 28 : 979-990, 1980. 